\title{
Trait bin and trait cluster accounts of human nature
}

\author{
Grant Ramsey \\ grant@theramseylab.org \\ www.theramseylab.org \\ Institute of Philosophy \\ KU Leuven \\ Belgium
}

Conceptions of human nature fall under two broad categories, trait bin accounts and trait cluster accounts. Trait bin accounts take there to be a special bin of traits, one composed of all and only those traits constituting our nature. For those arguing for a trait bin account of human nature, the challenge is to articulate what it is that marks a trait as being in or outside of the bin. For some, the bin is filled by the traits essential to being human. Others, such as Machery in his contribution to this volume, offer a nonessentialist trait bin conception of human nature. In this chapter, I argue that trait bin approaches to human nature are misguided, that there is no good way of dividing human traits into those that are a part of our nature and those that are not. Instead, I argue for a trait cluster account, which sees human nature not as a special bin of traits, but as the relationship among traits. Under this account, human nature lies in the patterns of trait expression within and across human life histories. This account does a superior job characterizing what humans are like and aligning human nature with the human sciences.

\section{Introduction}

Consider the mineral hematite, one of the chief sources of iron. What is the nature of hematite? One answer might involve reciting its formula, $\mathrm{Fe}_{2} \mathrm{O}_{3}$. This formula points to one of hematite's invariant properties, its ratio of two iron atoms for every three oxygen atoms. But stopping at the molecular formula would be rather dissatisfying - it offers only modest help in distinguishing hematite from other minerals, especially ones that can appear similar, such as magnetite. Furthermore, because $\mathrm{Fe}_{2} \mathrm{O}_{3}$ can occur in various 
polymorphs such as maghemite-which has a cubic crystalline structure, unlike the rhombohedral structure associated with hematite- $-\mathrm{Fe}_{2} \mathrm{O}_{3}$ does not uniquely identify hematite. Manifest properties, such as its colour or texture, can add valuable information, though in this case they can vary significantly. Hematite can appear dull or lustrous, and its colour can vary from black to grey to pale orange. The highly variable nature of these properties undercuts their use in helping to identify hematite. What are more stable are properties that would be realized only given certain counterfactual situations. For example, one invariant feature of hematite is the colour of its streak. The streak colour of a mineral is the colour achieved by scraping it on a streak plate, which is standardly a piece of unglazed porcelain. Thus, part of the nature of hematite might consist in what we would achieve were we to abrade it on a streak plate. Many other properties are of this kind. Were we to heat a sample of the mineral, at what point would it melt? Hematite nature is thus about the evident properties samples of hematite bear, but also, and perhaps more importantly, it concerns properties that samples do not bear but possibly would bear if certain things were to happen to them. ${ }^{1}$

Let's label the possible things that can happen to hematite the 'possible hematite lives' - the possible life histories that pieces of hematite could live, being crushed, weathered, heated, ground, suspended in water, etc. These possible lives will exhibit patterns from which generalizations can be drawn. If streaked, a red powder will appear. If heated to $\sim 1,500$ degrees centigrade, it will liquefy. We could thus imagine the set of possible hematite lives, and the properties of those lives. Lives that involve the property of being heated in excess of 1,500 degrees centigrade will result in the consequent trait of being a liquid; having a certain force applied will result in the sample being crushed, and so on. (These of course require certain "normal" background conditions to obtain, conditions that are implicit here but could be made explicit.) These generalizations are possible because of the patterns of traits that exist over the set of possible life histories. I suggest, therefore, that we can understand hematite nature as consisting in the clusters of traits dispersed over hematite possible life histories. Hematite nature is not a bin of traits,

\footnotetext{
${ }^{1}$ See, for example, http://geology.com/minerals/hematite.shtml for information on the properties of hematite.
} 
but instead a set of relations among traits. Call this the 'trait cluster account' of hematite nature.

The main claim of this article is that the trait cluster account is not just a good account of hematite nature, or mineral nature broadly considered, but also serves as an adequate account of human nature. In the case of hematite, it may be possible to describe its nature in terms of simple dispositions, where these traits are (largely) unmanifested dispositions. But when one considers biological organisms and their complex life histories, such dispositions will not work to capture the complex way in which traits are related to one another. Instead, a more nuanced understanding of trait patterns over life histories will be required. Rather than talking of a disposition to anger, say, it is more informative to take the trait of being angry and see which other traits it is related to and how they are related. My argument here for a life history-centred account of human nature is an expansion of my earlier (2013) proposal. In addition to articulating this account, I will draw out many of its implications and show how it enables conceptions of human nature to align with the human sciences. In defending the trait cluster framework, I will contrast it with the 'trait bin' approach, which characterizes human nature as a bin of traits instead of the relationships among traits.

Both the trait bin and trait cluster accounts are responses to the felt need for a concept of human nature that avoids the perils of essentialism. As Hull (1986) noted, since biological species (including Homo sapiens) are not defined in terms of essences, we cannot use species essences to construct a concept of human nature. The conclusion Hull drew was a skeptical one; he was skeptical about the project of producing and using a concept of human nature. The trait bin and trait cluster accounts attempt to avoid the perils of essentialism, while retaining the concept of human nature.

\section{The trait bin account of human nature}

There are two fundamentally distinct approaches to understanding the relationship between human traits and human nature. One approach - the trait bin approach - holds that human traits fall into two mutually exclusive bins: the nature category and the other category (containing, say, cultural or learned traits). The second approach-the trait 
cluster approach - takes human nature to consist not in a bin of traits, but in patterns of trait expression. The trait bin account will be considered here and the trait cluster account will be discussed in the following section.

Essentialist views of human nature are trait bin accounts. They place in the nature bin the traits essential to our species. But one need not be an essentialist in order to defend the trait bin approach. There are criteria other than being considered essential that one can use to sort traits into the nature and other categories. In this section I will consider and critique a recent attempt at defending a nonessentialist trait bin account, that of Machery (2008, 2016, this volume). In so doing, I will not be suggesting that his conception is a poor rendering of the trait bin approach. Indeed, it is a clever attempt to save the trait bin approach from the problems of essentialism. Instead, my critique extends beyond Machery's approach, showing that the trait bin approach itself is where the problems lie.

Machery argues that we should retain the human nature bin, but define it in terms other than essences. His proposal is that "human nature is the set of properties that humans tend to possess as a result of the evolution of their species" (2008: 323). Thus, traits fall into the human nature bin just in case they occur in "most humans" (2008: 323) - which I will understand to be more than 50 percent (though the precise percentage is not important for my critique) — and are a product of the evolution of our species. By "human," he means humans now, not ones that existed in our evolutionary past or ones that will exist in our future. And by "the evolution of their species" he does not mean only the traits that arose in our species, that is, since the origin of our species' lineage around two hundred thousand years ago. Instead, he means the evolution of our species as well as the species ancestral to ours. Thus, a trait like maternal care is, for Machery, in the human nature bin even though it preceded our species and is universal among mammals. The reasoning behind these criteria is that if human nature is meant to characterize humans, the included traits should be common. And by excluding traits not part of our evolution, Machery excludes traits "exclusively due to enculturation or to social learning" (2008: 326). ${ }^{2}$ Human nature is thus the common traits resulting from our

\footnotetext{
${ }^{2}$ I should note that Machery has modified his criteria in his contribution to this volume.
} 
evolutionary heritage.

There are many difficulties with these criteria. Although the 50 percent dividing line has intuitive appeal, many important human traits are possessed by a minority of humans. Women typically undergo menopause, and this appears to be a particularly interesting derived trait in our species. But because fewer than 50 percent of humans will undergo menopause, it is not part of human nature on Machery's view. Applying this criterion to hematite, the orange streak it leaves on a streak plate will not be a part of hematite nature since only a tiny fraction of hematite in the world has undergone or will undergo a streak. Machery could, of course, bite the bullet and argue that just because the streak is an important diagnostic tool does not mean that it is a part of hematite nature. But it is not clear that this is a bullet we need to or should bite.

The criterion that traits in the human nature bin must be a result of the evolution of our species and not "exclusively due to enculturation or to social learning" also has intuitive appeal. But which traits are exclusively due to enculturation or to social learning? Machery uses the example of the belief that water is wet: "the belief that water is wet is not part of human nature, in spite of being common, because this belief is not the result of some evolutionary processes. Rather, people learn that water is wet" (2008: 327). Is Machery right that there is nothing related to the evolution of our species that helps explain such a belief? This is of course a difficult empirical question, but it does not seem outlandish to think that evolved cognitive capacities shared by the majority of humans are involved in the formation of such beliefs. But if this is true, it is hard to think of beliefs (or other human traits) that are "pure" and free of any evolutionary influence. While Machery (2008: 327) anticipates this difficulty in acknowledging that "it is probably correct that evolutionary processes causally contribute to the existence of any

Partly in response to my (Ramsey 2013) earlier critiques, he has made his account closer to my life history trait cluster account: "it is natural to think that describing what human beings are like involves describing what they are like at the various life stages that constitute the life history of human beings" (Machery this volume: 000). And he also adds traits possessed not by individuals alone, but ones that "typical human groups tend to possess because of the evolution of their species" (000). These new additions, though improvements, do not undercut my critiques of the trait bin approach. 
trait that is common among humans," he does not answer the concern that there are deep problems inherent in trying to divide traits into two mutually exclusive categories, one due to evolution, the other not due to evolution.

In his contribution to this volume, however, he addresses this issue. He argues that "the nomological account requires one be able to distinguish those traits whose distribution is explained by appealing only to individual or social learning from other traits, not traits whose development is only influenced by individual or social learning from other traits" (000, italics in original). This is a slippery move, since given the pragmatics of explanation, it is possible that in many cases, we will be satisfied with an explanation of a trait distribution that only appeals to learning. It nevertheless should be acknowledged that explanations of the distribution of traits can often benefit by pointing to evolved psychological traits. For example, we might notice that in the English language the more common words tend to have fewer syllables than rarer words. We might be satisfied in explaining this distribution in word size by pointing out that this was true of the previous generation and that the current generation learned their language for the most part from that generation. The distribution of words length is thus explained purely by learning. Though some may find this satisfying, I think that pointing to psychological features of our species (attention spans, abilities to remember long words, etc.) may be more insightful in explaining such a distribution.

Another question concerns the criteria we should use to classify trait tokens into trait types. To say of a human behavioural token that it is part of an evolutionary process and has been a target of selection requires that this trait token be subsumed into a class of tokens that can be identified across generations. Machery uses the example of shame as a trait with an evolutionary history. Shame, of course, is manifested by particular shame tokens like "feeling shameful because of a failure to make the honour roll at school." Is such a behaviour the result of an ultimate explanation? This depends on how one partitions traits. If the group of traits includes only ones involving shame about schoolrelated performance, then this is unlikely to have a selective history. That is, there was probably not a sequence of ancestors that exhibited this particular behaviour and received a fitness boost because of it. Instead, if we subsume such behaviour into a broader class 
of traits that share a common etiology, in this case behaviours that are strongly connected to the emotion shame, then we might be able to offer an evolutionary account. Returning to the example of knowing water to be wet, the questions for Machery are to which class of traits this belongs, what unifies this class, and what justifies grouping the tokens into this class and not another? Once these questions are answered, we can ask whether the disposition uniting the tokens has been selected for. One intuitively subsumes shameladen behaviour into the shame-caused category, but what is the right category to subsume other traits like knowing water is wet? Machery needs to offer a framework for connecting trait tokens (token instances of shame or beliefs about water) with underlying dispositions before making his conclusion about which ones are the result of an evolutionary history.

With Machery's criteria, it is also difficult to know how to categorize quantitative traits (traits that can take on a range of values) instead of qualitative traits (traits an individual either possesses or does not). Take human height. Is it human nature to have a specific height? Heights have changed considerably over the past century or so, in part due to cultural (especially dietary) changes. In the Netherlands, for example, male height has increased by almost 13 percent since the mid-nineteenth century, a fairly dramatic increase (Schönbeck et al. 2013). A quantitative trait like height thus raises two problems for Machery. First, does the fact that each human has (measured at a very fine grain) a unique height mean that height is not a part of human nature? Second, does the fact that the environment (cultural or otherwise) plays an important role in the trait expression mean that it is not part of human nature? Since many important human traits are quantitative, it seems that they should not be eliminated from human nature. Thus, such questions pose deep problems for a trait bin account of human nature. A better approach to answering these questions would be to investigate the range of values of human height and the way these values are related to such things as diet. Such a way of understanding human nature is what will be argued for below. But first, let's take stock of the critique of Machery's position and what it implies for the tenability of a trait bin approach.

Machery's account was challenged based on how it attempts to sort traits into the human nature bin. His approach has problems generated by including only majority traits, 
and by excluding traits that are clean of evolutionary influence. I suggest that it is not just Machery's rendering of the trait bin approach that is problematic, but the approach itself. To see this, let's step back and consider how traits come about.

All human phenotypic traits are the result of development. They represent a complex interplay between our genes and environment (including our cultural environment), both of which have been passed down from our ancestors. Some traits are relatively well buffered against a range of differences in genes; others consistently develop over a wide range of environments. The degree to which environmental and genetic differences affect any particular trait can take on a wide range of values.

Furthermore, the degree to which differences in properties of organisms can be linked to genetic differences critically depends on the background environment. Some environments set up organisms to be very sensitive to particular genetic differences, while other environments may render these genetic differences impotent. My suggestion is that if we consider the set of possible gene-environment combinations, and the traits that these generate, there is no justifiable, nonarbitrary way of sorting these traits into two bins, one bin of traits belonging to the nature of our species, the other bin of traits not so designated. Because of this, I hold that the trait bin approach to characterizing human nature should be abandoned.

Machery's response in this volume to this argument counters that the explanation of trait distributions is always contrastive and that some traits can only be explained in terms of social or individual learning: "To explain why some traits are typical one can appeal to ultimate causes; to explain why other traits are typical, one can only appeal to individual or social learning. The former, but not the latter, are part of human nature" (this volume: 000, italics in original). He provides an example of something that can only be explained in terms of social learning:

For instance, if a few years ago most human beings had learned Psy's song "Gangnam Style," one would not provide a proper explanation of this explanandum by appealing to the evolution of the larynx and the vocal chords or the evolution of the human musical sensitivity (e.g., Mithen, 2005) since 
evolutionary information would not be specific to the contrast between Psy's song

“Gangnam Style” and Carly Rae Jepsen's “Call Me Maybe.” (this volume: 000)

But how, I wonder, does Machery rule out explanations based on evolved traits? How any particular song spreads is going to be a function of such variables as the characteristics of the song and the underlying neurophysiology. Perhaps "Gangman Style" resonated with people more than "Call Me Maybe" because it stimulated our (evolved) limbic system in ways that gave us greater pleasure or excitement. Pointing this out may not be a very satisfying explanation, but it suggests that we cannot simply assume a priori that explaining the difference in song performance will never benefit from citing evolved characteristics. Similarly, another of Machery's examples, why so many Americans know “The Star Spangled Banner," surely at least in part involves (evolved) traits concerning tendencies to conform with those around you. Thus, while I agree that we are sometimes satisfied with explanations which point out that something was socially or individually learned, many times we want to go further, to know why one thing was learned and not another.

In sum, the trait bin approach is subject to a host of problems. My solution for human nature, the trait cluster account, will be explored in the next section.

\section{The trait cluster account of human nature}

In Hamlin Garland's autobiography, he notes that "to rob me of my memories of the circus would leave me as poor as those to whom life was a drab and hopeless round of toil. It was our brief season of imaginative life. In one day — in a part of one day —we gained a thousand new conceptions of the world and of human nature" (1917: 137). Circuses are known for their idiosyncratic characters and odd - if not bizarrebehaviours. Thus, we are faced with a dilemma. Either Garland - and others who think we can learn about human nature by studying the full range of human behaviour-is wrong, or Machery's trait bin approach is wrong and it is not the high frequency of traits across the whole species that is essential to human nature. 
In this section, I articulate and defend what I call the trait cluster approach to human nature. This approach requires a gestalt shift in how human nature is understood. Traits are not taken to be within or outside of human nature. Instead, human nature lies within the patterns of expressions of the traits. To see this shift, consider how we would characterize the nature of a baseball. Under the trait bin approach-Machery's version of it at least, which he labels the nomological account-we would look for properties that are frequent among baseballs and a part of baseball history. Traits included in the baseball nature bin might be spending most of their time sitting still indoors or being made of leather, since these traits, though not universal, are a part of the majority of baseballs. By contrast, the trait cluster approach does not hold that there is a bin of traits constituting baseball nature. Instead, the nature of a baseball lies in how it performs in various circumstances. When hit with a bat with a particular angle and velocity, how much is it deformed and how far will it travel? Baseballs do not act outside of their nature, but this does not mean that they do not have a nature, or that they have an overly permissive nature. Baseballs act in very specific, reliable ways given their particular environmental inputs, and it is their nature to do so. Paralleling the hematite example above, nothing samples of hematite do goes against hematite nature, but this does not mean that hematite nature is overly permissive or vacuous. Instead, hematite trait clusters are very specific and very informative in distinguishing hematite from other minerals and in explaining patterns of traits among samples of hematite.

Before articulating in detail my account of human nature, let's consider whether there have been other trait cluster conceptions of human nature. I will focus here on Griffiths (2009) and Cashdan (2013), since their views come the closest to my own by placing patterns of trait variation on centre stage.

Griffiths argues that "the primary sense which should be attached to the term 'human nature' is simply what human beings are like, not some cause that makes them that way. As such, human nature is primarily the pattern of similarity and difference amongst human beings" (2009: 53). Griffiths, here, is arguing against a hidden, inner nature that causes manifest traits. This argument is born out of his antiessentialism: it is simply false that each human contains within himself or herself the essence of our 
species, and that this essence causes our behaviour. Griffiths, however, does not adopt Hull's (1986) sceptical solution that there is no such thing as human nature, nor does he accept Machery's solution of offering an antiessentialist trait bin account. Instead, for Griffiths, human nature is about patterns of similarity and difference among human beings. The account I will offer goes a bit further than this, taking human nature to reside not just in the patterns of similarity and difference across human beings, but also in the way traits are patterned within individual life histories. But before fleshing this idea out, let's consider another trait cluster account, that of Cashdan. As she argues,

because human nature evolved to be flexible in predictable ways, the task of understanding human nature requires that we understand how evolution shaped that variation. The assumption is not just that we evolved flexibly, but that selection shaped the nature and direction of that flexibility. To a behavioral ecologist, then, the predictable, patterned nature of that response is the universal we must understand. In this view, we cannot understand our universal human nature without understanding the variability in its expression...The concept is clarified by viewing variation as a norm of reaction - the pattern of expression of a genotype across a range of environments. (2013: 71)

Cashdan thus holds that human nature consists not in a set of traits, but instead in patterns of trait expression. She is thus rejecting a trait bin account and endorsing the trait cluster approach. She is primarily interested in one kind of pattern: how genotypes are expressed differently over a range of environments. Understanding human nature, then, is based on understanding how evolution shaped our ability to flexibly and predictably adapt to different environments. While I agree with Cashdan that patterns of gene expression across environments are an important component of the trait cluster account of human nature, they do not exhaust human nature.

One other account I should mention before introducing my version of the trait cluster account is that of Samuels (2012). He labels his view essentialist, but it is not essentialist in the way the term is standardly understood. As Samuels argues, "human 
nature is a suite of mechanisms that underlie the manifestation of species-typical cognitive and behavioral regularities" (2012: 3). This view is in some ways not too far off from my own, since it concerns patterns of traits and the investigation of what underlies these patterns. But I don't think that it is helpful to restrict human nature to mechanisms. First, this intertwines human nature with debates about what a mechanism is. Second, as Machery (2016) points out, if we want human nature to describe what we are like, we should not restrict human nature to mechanisms. Of course, Machery holds that one should instead offer a bin of traits, whereas I hold that one should be concerned with how the traits are associated. I will now describe in detail my version of the trait cluster account.

I previously proposed a trait cluster account of human nature, which I labelled the life-history trait cluster (LTC) account because it is based on patterns of traits over sets of human life histories (Ramsey 2013). I will retain the 'LTC' label in order to differentiate my account from other trait cluster accounts like that of Griffiths and Cashdan. The idea behind the LTC account is this: Each individual human lives his or her life, and in so doing realizes a life history. This life history is their path through space and time and contains all the traits they have exhibited over their lifetime. The one life history that any particular human realizes is not the only way he or she could have lived over his or her life. Given the genes and the environmental arena in which the individual resides, there is a set of possible ways that he or she could have lived his or her life. (This is not a claim about indeterminism - instead one can speak of possibilities in deterministic systems, like possible games of pinball given possible starting states and game plays.) Each of these possible life histories can be understood as a four-dimensional structure, and this structure is populated with traits. These organismic traits can occupy the whole life history, but will frequently occupy only a subset of each life history. Having blood coursing through our veins is something each of us will have for our entire lives, unless we experience a cardiac arrest from which we are able to recover. And being asleep is a trait that we experience during roughly one-third of our life history, cycling on and off. Other traits, like adult teeth, are not inborn (though their buds are), but once we have them they usually stick around for the entire remainder of the life history. "Trait" in this 
sense is thus used quite liberally; even a hiccup, sneeze, or yawn issued at a particular time is a trait.

Let's now examine how this set of life histories links up with human nature. It is clear that for any individual, while they have - at a fine grain of analysis - an immense number of possible lives that they can lead, the pattern of traits is nevertheless rather constrained (holding fixed their genes and the extant environmental arena ${ }^{3}$ ). They are constrained in the obvious sense that some traits simply cannot arise - no human will hibernate or sprout wings and fly-but there are subtler and more interesting constraints as well: Traits that are a part of at least some possible life histories ("possible lives" for short) will nevertheless be limited by such things as age and the sequence of preceding traits. Adult teeth erupt following (and not before) baby teeth; mothers lactate following (and not before) pregnancy; pregnancy only happens between menarche and menopause. While there may be exceptions to such generalizations, there are nevertheless patterns to how the traits are distributed over life histories.

It is these patterns, and the generalizations we can derive from them, that constitute individual nature, the nature of an individual organism, that is. Similarly, the nature of a particular baseball is based on the possible ways it will behave over its life. If hit in certain sorts of ways, it will be propelled for long distances. If it is lost in the woods, it will slowly decompose, but will do so in a predictable way. If it is exposed to prolonged hot, dry weather, it will predictably form small cracks. Thus, we could map out the possible fates of the baseball, and note the pattern of trait expression over the set of possibilities. Such patterns, and the generalizations we can draw from them, constitute the nature of the ball. If the ball is hit but does not burst into flames, we can note that such a flight is not a part of this ball's nature. The baseball's nature can thus serve to explain its outcomes.

Because of the laws of physics, especially under some interpretations of quantum mechanics, the ball has a nonzero probability to, for example, spontaneously jump from the pitcher's hand to the top of her head. This behaviour is therefore within the ball's

\footnotetext{
${ }^{3}$ If one does not hold these fixed, then it is no longer clear that it is human nature that is being articulated. More on this below.
} 
nature, though it has such a small probability that it can be ignored. Similarly, the nature of an individual human will include countless highly improbable events. And, as with the ball, they can safely be ignored despite their inclusion within the individual's nature.

Let's now define individual nature precisely: An individual's nature is the pattern of its trait expression over its set of possible life histories. (Again, this is holding fixed the individual's set of genes and environmental arena, and of course the laws of nature. If genes were allowed to vary, individual nature would be vacuous since sufficient changes to genes could, say, change an American into an aardvark. By contrast, varying the way that an individual encounters its environmental heterogeneity reveals something about its nature.) Individual nature thus includes both the patterns within individual life histories, as well as the patterns across those life histories. Individual nature, however, is not human nature; it is instead its foundation. Consider the individual nature of each human. If we were to combine the possible life histories from each individual's nature, then we would have human nature: Human nature is the patterns of trait expression over the totality of extant human possible life histories. Because humans are an evolving species — not something with a static nature like a chemical element—human nature is restricted to extant humans (in the sense of extant genomes and sets of environmental variables). The benefit of this is that it allows human nature to change over time, and does not require of human nature that it take into account the deep past.

This account of human nature - the LTC account—by concerning patterns of trait expressions, does not directly concern the actual frequency of traits. While the frequency of traits can serve as evidence for human nature, actual frequency per se is not definitionally linked to human nature, as it is in some trait bin accounts. I argued in the introduction that the natures of scientific kinds like hematite are best defined not in terms of the bin of traits that most pieces of hematite bear, but instead in terms of the patterns of expressions of the traits within the space of possible hematite lives. These patterns carry more information about the nature of hematite and are more helpful in distinguishing hematite from other, similar minerals. Hematite nature, and mineral nature broadly considered, are thus the subject of the mineralogical sciences. Scientists don't just passively observe and tally the manifest properties of minerals; instead, they do 
things to the minerals and see how traits like being bathed in hydrochloric acid are associated with changes in the mineral. And just as an LTC account of mineral nature allows mineral nature to be aligned with the mineralogical sciences, so does the LTC account of human nature allow for human nature to be aligned with the human sciences. But before arguing for a link between the LTC account of human nature and the human sciences, let's step back and consider what roles human nature might be expected to fulfil, and whether the LTC account can fulfil them better than a trait bin account.

\section{What is human nature good for?}

I have argued that there is a concept of human nature, the LTC account, that does not fall prey to the same difficulties as trait bin accounts. But in order to see whether the trait cluster approach is truly superior to the alternatives, we must pause to consider what the concept of human nature is for, what use it can have.

The fact that 'human nature' has currency in the academic and popular media urges us to respond in one of two ways. One way is to hold that 'human nature' is like 'phlogiston' - it is a term without a referent within the contemporary worldview. It should thus be discarded and replaced with one or more new concepts, just as phlogiston is now taken not to be a substance, but instead the absence of oxygen. ${ }^{4}$ Could human nature have a similar replacement? The problem with finding a replacement is that human nature does not play a specific, technical role in the sciences. It is less like a theoretical posit and more like a name for the general subject of the human sciences: human nature is the quilt and the various sciences concern patches on this quilt. If this is true, then we should pursue the second way of responding, which is to produce a clearer notion of what human nature is. Such a conception should (1) articulate the subject of the human sciences. In so doing, it might help to (2) characterize what human beings are like and may even be used to (3) causally explain what we are like. Other desiderata might include (4) articulating human limits, (5) distinguishing humans from other animals, and (6) providing normative insight about how humans should be. In what follows in this section,

\footnotetext{
${ }^{4}$ This is to gloss over the complexities of the case of phlogiston-see, for example, Chang (2009).
} 
I will consider desiderata 1-3 to see which of these roles the LTC can play, and will compare the results to the roles played by Machery's nomological account. For a discussion of 4 and 5, see Ramsey (2013); for a discussion of 6, see Ramsey (2012, 2017).

\subsection{Human nature as the subject of the human sciences}

If human nature is not based on intuition or religious texts, but is instead based on what we do and how and why we do it, human nature should be aligned with the human sciences. We can thus consider human nature to be the subject of the human sciences. Thus, to see whether the LTC account of human nature is tenable — and superior to trait bin approaches - we should consider what the human sciences are after and what kinds of results they consider to be worthy of reporting.

The human sciences are diverse and include such disciplines as psychology, sociology, anthropology, and economics. In comparing trait bin and trait cluster accounts, the task at hand is to see whether these sciences are primarily concerned with how traits are related to one another, and to see if the sciences restrict their domain of enquiry toin Machery's rendering - traits that are possessed by the majority of humans and are due to human evolution. Let's focus on one of the sciences, psychology. Machery's (2008) paper was published in the journal Philosophical Psychology, and he certainly has psychology as a target science. Should we then conclude that psychological science centres on traits that are evolutionary products that the majority of humans possess? This is of course an empirical question, and the rigorous survey of psychology capable of decisively answering it is beyond the scope of this article. But to get a flavour for what psychology tends to focus on, let's consider the subject matters of the papers the official journal of the American Psychological Society, American Psychologist, publishes, and whether they tend to concern the bin of traits identified by Machery as human nature, or instead associations among traits.

For a sample, let's examine the first article in each issue in volume 70 of American Psychologist (up to October 2015, which is the most recent volume at the time of this writing). The first article of issue 1 concerns the promises of qualitative inquiry, so 
it does not directly bear on the matter of human nature. The second article of the issue, "Evaluating gender similarities and differences using metasynthesis," concerns ways of evaluating how similar traits are across genders. This is clearly about trait clusters, and is not about the majority of traits that are products of our evolution. Moving on to issue 2, the first article is "Cancer control falls squarely within the province of the psychological sciences." This article concerns topics like "evidence linking certain behaviors to cancer risk and outcomes" (Green McDonald et al. 2015: 61). The article is thus clearly about associations among particular behavioural traits and certain forms of cancer occurring in the minority of the population. The first article in issue 3 is "National accounts of subjective well-being," which discusses associations among well-being traits and policyrelevant factors. Issue 4, a special issue on bullying, clearly concerns trait associations. For example, the first article after the introduction (McDougall and Vaillancourt 2015), "Long-term adult outcomes of peer victimization in childhood and adolescence: Pathways to adjustment and maladjustment," is about how childhood bullying traits are clustered with traits in adults. Issue 5 concerns lists of achievements, awards, and obituaries. The first article of issue 6 is about the replication crisis and the role of sample size and is thus less directly relevant to the issue at hand. Issue 7 is a special issue on mindfulness. The first article, "Conceptual and methodological issues in research on mindfulness and meditation," is a methodological article that deals with issues such as "the nature of control and comparison conditions for research that includes mindfulness or other meditation-based interventions" (Davidson and Kaszniak 2015: 581). This paper focuses on patterns of associations among traits, in this case meditation-based interventions and other traits.

While it may be that this small survey of American Psychologist is not representative of the whole of psychology, or the human sciences broadly considered, I consistently find in this and other samples of the literature studies that concern one kind of trait (meditating, say) and its association with other traits (like stress levels). I tend not to find studies that restrict their domain of inquiry to traits that the majority of humans possess, or traits that have an evolutionary heritage. Generalizing from this sample, I am confident that if we want human nature to be the subject of the human sciences, human 
nature must concern associations among traits, not a bin of traits. The LTC account, therefore, to fulfils the desideratum of having human nature be the subject of the human sciences. Downes (2016) argues of trait cluster approaches that "their most fruitful contributions are not their alternate characterizations of human nature. Rather, they each provide alternate, evolutionarily influenced frameworks for understanding and explaining human variation, both of which are valuable resources for social scientists confronting human variation" (919). But if human nature is the subject of the human sciences, it appears that the LTC account is a good approach for understanding human nature, and is certainly better from methodological and empirical standpoints than alternative trait bin accounts.

Machery and other trait bin theorists might reply that this is simply not a desideratum of a conception of human nature. Of the five traditional desiderata he lists in his (2016) article, he does not include human nature being the subject of the human sciences. But if human nature is disconnected from the human sciences, two problematic conclusions follow. One is that human nature will have arbitrary boundaries. The 50 percent criterion of Machery seems arbitrary, and using the sciences as our guide, we don't need to produce a priori boundaries like this. The second conclusion is that if human nature is free floating and independent of the human sciences, then we have the odd situation that most human scientists are not concerned with discovering human nature; rather, they only accidentally discover features of human nature when they happen to focus on the right bin of traits. Furthermore, if the sample of papers from American Psychologist is indicative of the human sciences, scientists very rarely study human nature in Machery's nomological sense. Thus, under the nomological account, human nature and the subject of the human sciences are minimally overlapping. But if this is true, it is difficult to see what the point is of retaining the concept of human nature. In order to see why we should retain the concept of human nature, let's consider other desiderata and whether the trait bin approach might better satisfy them.

\subsection{What are humans like?}


Even if the conception of human nature that emerges from the nomological approach is not the subject of the human sciences, perhaps the approach is nonetheless useful for describing what we are like. Machery certainly thinks his account fulfils this desideratum: The nomological account "fulfills the descriptive function; indeed, it was developed to fulfill it" (2016: 214). But does his approach really do an adequate job characterizing human nature in this purely descriptive way? One difficulty, mentioned above, is that many traits of central importance to our species do not occur in the majority of individuals. This is true of many species. It is an important feature of chimpanzees that there is a status hierarchy and that there are alpha males and alpha females. This does not lose its importance if we realize that only a minority of chimpanzees will ever achieve alpha status. Another difficulty is that so much of what humans are like involves not a set of traits, but, as we've seen, the relation among traits. Just as describing a chemical compound by listing a bin of constituent elements will provide much less insight than noting how the elements are bonded to one another, so noting how human traits are bonded to one another and distributed over life histories is where the deep insights about human nature come from.

Nevertheless, Machery holds that his nomological approach is a superior account in characterizing humans:

Because the nomological notion of human nature fulfills the descriptive function, human nature has predictive power: It allows scientists and lay people to make probabilistic predictions about how people are going to behave in particular situations. This is [in] line with the use of the notion of human nature in the sciences. For instance, Gintis $(2008,1346)$ makes the following prediction about a behavioral-economics game: "Because the four subjects are strangers, the standard view of human nature suggests that there will be zero contributions." (2016: 215)

But is human nature as Gintis is using it a good fit with the nomological approach? Gintis's paper quoted by Machery concerns economic games studying punishment and cooperation across cultures. Gintis claims that "the standard view holds that human nature has a private side in which we interact morally with a small circle of intimates and 
a public side in which we behave as selfish maximizers" (2008: 1346). Gintis then goes on (in the text quoted above by Machery) to note what this standard view entails about how strangers should interact. He later points out that "in the many times this game has been played in a variety of social settings, the older view [of human nature] is virtually never supported" (2008: 1347). In the particular study discussed by Gintis, he points out that "antisocial punishment was rare in the most democratic societies and very common otherwise" (2008: 1346).

In sum, Gintis offers a simple conception of human nature and notes that it is not born out by the data. Instead, the data show that human nature is much more complex, that depending on the cultural milieu, different traits will predictably appear. Exposure to a democratic worldview results in one set of cooperation and punishment strategies, while an absence of democratic exposure results in another. Human nature in this case is best understood in terms of a pattern of economic decision outcomes and their relation to prior life history traits. Such a finding about human nature is easily accommodated by the LTC account, but I fail to see how the nomological account has predictive power in this case. First, it is not clear that any one of these cooperation and punishment strategies exists in more than 50 percent of the world population. Second, Machery's separation of human nature from culture and learning is problematic. The results discussed by Gintis are clearly modulated by cultural influence and social learning, yet the predictable associations of upbringings and economic decision outcomes help to reveal human nature.

Machery (2016) uses the following case both to highlight the predictive power of his account, but also to criticize my trait cluster account:

Ramsey's notion of human nature seems to have little predictive power. Because every phenotype that a human being could have belongs to one of the life histories included within human nature, on this notion one cannot justifiably infer that a human being is likely to possess a trait from the fact that this trait belongs to a life history included within human nature. (Machery 2016: 216) Machery's critique misses the point. When we make predictions about which traits an individual will bear, we usually do not do so in the total absence of knowledge about 
them. Instead, we make predictions based on what other life history traits they bear. Following Gintis's discussion, we would predict one form of behaviour from individuals in democratic societies, another from individuals in other societies. In fact, one of the major conclusions of Gintis's discussion is that we need such information in order to make robust predictions about human behavior. Thus, the fact that human life histories are heterogeneous is not a problem so long as we recognize that the heterogeneity is not random; it follows predictable regularities and results in predictable patterns of outcomes.

\subsection{Causally explaining human characteristics}

At the heart of the essentialist view is the idea that each of us has within us a uniquely human essence. And in at least some renderings of the essentialist account, we can cite this essence in explaining the nature, frequency, and distribution of human traits. But do nonessentialist trait bin accounts or the LTC account allow for causal explanations of human characteristics? As Machery points out, his conception of human nature "is not viewed as a cause; rather, it is constituted by the outcomes of various evolutionary processes. . Thus, it is unclear how the notion of human nature could underwrite causal explanation of human beings' characteristics" (2016:218).

Machery's account cannot causally explain outcomes, but he nevertheless holds that "human nature can be a causal-explanatory notion despite not being a cause" (2016: 219). This is because, for him, human nature "is an etiological kind: All the properties of human beings that are included in human nature have the same etiology in that they are the outcomes of evolutionary processes. As is the case with other etiological kinds, classifying a trait as belonging to human nature is thus to endorse a particular explanatory sketch: It is to assert that this trait is a proper target of an ultimate explanation" (2016: 220). In other words, because his trait bin is composed only of traits that have an evolutionary history, to claim that a trait is part of human nature is to claim that it has an evolutionary history. Thus, any causal generalizations we can make about traits with evolutionary histories are generalizations that we can apply to human nature traits.

The causal explanatory power of the nomological account is rather weak, but Machery thinks it does a better job than the LTC account: "The causal-explanatory 
function is largely left unfulfilled by Ramsey's life-history trait cluster account of human nature. Every possible trait belongs to some life history included within human nature, and so asserting that a given trait is due to human nature provides no information at all. In this respect at least, human nature is not explanatory" (2016: 221). But Machery seems to be treating the LTC account as though it were a trait bin account. And he is right that if it were a trait bin account that included all traits, saying of a trait that it is in the human nature bin would carry no information. But the LTC account is a trait cluster account, not a trait bin account. There are therefore no traits within or outside of the human nature bin, since there is no such bin. Human nature consists in the relations among traits, not in features of a bin of traits.

Given that the LTC account is a trait cluster account and not a trait bin account, we can ask whether the LTC account, properly understood, can be used to causally explain human characteristics. If human nature is the subject of the human sciences, then the generalizations about trait clusters that are unearthed by science can serve as part of the explanans in explanations of human characteristics. And to the degree that such associations are causal, explanations in terms of these associations will be causal explanations. For example, if meditating lowers your stress, you can cite human nature to account for it, since psychologists have confirmed that meditation is associated with lower stress. And researchers do not stop at mere associations, but try to uncover reasons why the associations obtain: Which causal pathways connect meditation behaviour with lower levels of stress? Thus, pace Machery, the LTC account not only can causally explain human characteristics, but it also does a much better job than his nomological account.

\section{Conclusions}

Accounts of human nature fall into two broad categories, trait bin and trait cluster accounts. Trait bin accounts consider human nature to consist of a bin of traits. Trait bin accounts can be essentialist, in which the human nature bin is furnished only with traits essential to our being human. And there are nonessentialist trait bin accounts of human nature, like that of Machery $(2008,2016$, this volume), which define human nature as a 
bin based on properties other than essences.

The essentialist trait bin approaches are problematic because of the problems associated with attempting to maintain species essentialism in light of the nonessentialist contemporary phylogenetic classification system. Hull (1984) argued that the fact that natures are essences, and that species are not defined in terms of essences, shows that there is no such thing as human nature. Others have responded to this by arguing that there are nonessentialist trait bin or trait cluster conceptions of human nature that serve useful roles, and thus that the concept of human nature should not be abandoned.

The nonessentialist trait bin approach that I considered in detail here, Machery's nomological account, has merit, but bears a number of problems. The nomological account requires that for a trait to be included in the human nature bin, it must be exhibited by at least 50 percent of the members of our species. This seems rather arbitrary, but more importantly, it leaves out many traits that are centrally important to characterizing our species and distinguishing it from others. And the requirement that the traits have an evolutionary, not cultural, cause runs into several difficulties. But beyond these difficulties, it is not clear that the nomological account can fulfil core desiderata for human nature, such as aligning human nature with the human sciences.

The failure of both essentialist and nonessentialist trait bin accounts motivates my trait cluster account of human nature, the LTC account. Trait cluster accounts hold that human nature lies not in which traits individual humans happen to have, but in the way the traits are exhibited over human life histories. In particular, traits are distributed in specific patterns over human life histories, and it is in these patterns where our nature lies. These patterns can be used to characterize humans, and the patterns of trait associations are precisely what the human sciences are concerned to uncover and to explain. Thus, if we want to retain a conception of human nature that is capable of being the subject of the human sciences, then it is the LTC account that we should adopt. 
This is a preprint of a chapter whose final and definitive form is published in: E. Hannon and T. Lewens (eds) Why We Disagree about Human Nature, Oxford University Press. Please do not quote this version without permission.

\section{Acknowledgments}

Thank you to Michael Deem, Hugh Desmond, Tim Lewens, and Edouard Machery for taking the time to carefully read and comment on earlier drafts of this chapter. This article was completed while I was on a National Endowment for the Humanitiessupported fellowship at the National Humanities Center. I thank the NEH and NHC for their support. Any views, findings, conclusions, or recommendations expressed in this article do not necessarily reflect those of the National Endowment for the Humanities.

\section{References}

Cashdan, E. (2013) 'What is a human universal? Human behavioral ecology and human nature', in S. M. Downes and E. Machery (eds) Arguing about Human Nature: Contemporary Debates, New York: Routledge, pp. 71-80.

Chang, H. (2009) 'We have never been whiggish (about phlogiston)', Centaurus, 51: $239-64$.

Davidson, R. J., and Kaszniak, A. W. (2015) 'Conceptual and methodological issues in research on mindfulness and meditation', American Psychologist, 70(7): 581-92.

Downes, S. (2016) 'Confronting variation in the social and behavioral sciences', Philosophy of Science, 83: 909-920.

Garland, H. (1917) A Son of the Middle Border, New York: Macmillan.

Gintis, H. (2008) 'Punishment and cooperation', Science, 319: 1345-6.

Green McDonald, P., O’Connell, M., \& Suls, J. (2015) ‘Cancer control falls squarely within the province of the psychological sciences', American Psychologist, 70(2): 61-74.

Griffiths, Paul E. (2009) 'Reconstructing human nature', Arts: The Journal of the Sydney University Arts Association, 31: 30-57.

Hull, D. L. (1986) 'On human nature', PSA: Proceedings of the Biennal Meeting of the Philosophy of Science Association, 2: 3-13.

Machery, E. (2008) 'A plea for human nature', Philosophical Psychology, 21(3): 321-29. 
Machery, E. (this volume) 'Doubling down on the nomological notion of human nature', in E. Hannon and T. Lewens (eds), Why We Disagree About Human Nature, Oxford: Oxford University Press, pp. 000-000.

Machery, E., (2016) 'Human nature', in D. Livingstone Smith (ed.), How Biology Shapes Philosophy, Cambridge: Cambridge University Press, pp. 204-226.

McDougall, P., \& Vaillancourt, T. (2015) 'Long-term adult outcomes of peer victimization in childhood and adolescence: Pathways to adjustment and maladjustment', American Psychologist, 70(4): 300.

Mithen, S. (2005) The Singing Neanderthals: The Origins of Music, Language, Mind and Body, London: Weidenfeld \& Nicholson.

Ramsey, G. (2012) 'How human nature can inform human enhancement: A commentary on Tim Lewens's human nature: the very idea', Philosophy \& Technology, 25(4): 479-83.

Ramsey, G. (2013) 'Human nature in a post-essentialist world', Philosophy of Science, 80(5): 983-93.

Ramsey, G. (2017) 'What is human nature for?' in A. Fuentes and A. Visala (ed.) Verbs, Bones and Brains: Interdisciplinary Perspectives on Human Nature, Notre Dame: University of Notre Dame Press, pp. 217-230.

Samuels, R. (2012) 'Science and human nature', Royal Institute of Philosophy Supplement, 70: 1-28.

Schönbeck, Y., Talma, H., van Dommelen, P., Bakker, B., Buitendijk, S. E., HiraSing, R. A., and van Buuren, S. (2013) 'The world's tallest nation has stopped growing taller: the height of Dutch children from 1955 to 2009', Pediatric research, 73(3): $371-7$. 